Leslie E. Drane, INDIANA UNIVERSITY BLOOMINGTON, lesdrane@indiana.edu Jordan Lynton, INDIANA UNIVERSITY BLOOMINGTON, jylynton@indiana.edu

YaríCruz-Rios, INDIANA UNIVERSITY BLOOMINGTON, ycruzrios@gmail.com Elizabeth Watts Malouchos, INDIANA UNIVERSITY BLOOMINGTON, eliwatts@indiana.edu Katherine Kearns, INDIANA UNIVERSITY BLOOMINGTON, kkearns@indiana.edu

\title{
Transgressive Learning Communities: Transformative Spaces for Underprivileged, Underserved, and Historically Underrepresented Graduate Students at Their Institutions
}

\section{ABSTRACT}

In this article, we propose a new vision of educational development that reimagines how graduate instructors are socialized and professionalized in academic settings. We describe a transgressive learning community that empowers graduate instructors with tools to reveal, mitigate, and disrupt oppressive structures in higher education. Our learning community is founded on critical race and feminist conceptualizations of pedagogical inquiry in its design, implementation, and assessment to serve underprivileged, underserved, and historically underrepresented graduate students. We argue that the intersections of marginalized and graduate student identities create distinct experiences of discrimination, marginalization, tokenism, isolation, and impostor syndrome due to a lack of sustained teaching mentorship within the academy. The transgressive learning community model that we propose in this article functions to create spaces of transgressive and transformational pedagogical engagement for graduate students who exist at the intersections of these identities.

\section{KEYWORDS}

underrepresented minorities, graduate students, learning communities, critical pedagogy, feminist pedagogy

\section{INTRODUCTION}

We write from the borderlands (Anzaldúa, 1987) as members of underrepresented groups within academia - a collective including people of color, women, first generation students, second generation immigrants, members of the lesbian, gay, bisexual, transgender, and queer plus community, and differently abled individuals - who have experienced the challenges marginalized people face as instructors within the classroom. We also write as graduate students who understand how our experiences of marginality within the classroom are amplified by our liminal authority as students, rather than tenured faculty. We argue that the intersections of our marginalized and graduate student identities create distinct experiences of discrimination, marginalization, tokenism, isolation, and impostor syndrome due to a lack of sustained teaching mentorship and authority within the academy (Gutiérrez y 
Muhs, Niemann, González, \& Harris, 2012; Harris, Sellers, Clerge, \& Gooding, 2017). We propose a new space of educational development wherein we reimagine how graduate instructors are socialized and professionalized in academic settings. In this article, we describe a transgressive learning community that empowers graduate instructors with tools to reveal, mitigate, and disrupt oppressive structures in higher education. We borrow the term transgressive learning community in part, from bell hooks's 1994 Teaching to transgress: Education as a practice of freedom, which has inspired us, both individually and collectively, to view our discomfort within the academy as an opportunity to create new spaces of inquiry.

The model of a transgressive learning community that we propose is a direct response to boundaries we have experienced within the academy. These boundaries include what a teacher should look like; what behaviors teachers are allowed to perform in the classroom; what literature teachers should engage in; what good teaching means; and the roles of teaching centers and other spaces of institutional support. Thus, we offer the transgressive learning community as a safe space of transgressive and transformational pedagogical engagement for graduate students who exist both at the intersections of these identities and at the margins of who belongs in higher education.

Our learning community builds upon frameworks, including counter-spaces (Solórzano, Ceja, \& Yosso, 2000; Solórzano \& Yosso, 2002; Solórzano \& Villalpando, 1998), self-study methods (Foot, Crowe, Tollafield, \& Allan, 2014), and faculty learning communities (Richlin \& Cox, 2004), pairing them with a critical race and feminist approach to pedagogical inquiry in its design, implementation, and assessment. Inhered within the model of the transgressive learning community, as well as within its title, is a philosophy of transgression. Here, we use hooks's definition of transgression as "a movement against and beyond boundaries" (1994, p. 12). Thus, transgression evokes ideas of pushing, breaking, dismantling; it is traversing fixed boundaries to pursue change. In utilizing the term transgressive, our idea of a transgressive learning community provides a new way of envisioning underprivileged, underserved, and historically underrepresented bodies - traditionally perceived as transgressive by institutions of higher education - to be the very people that can transform classrooms and spaces within the academy to become transgressive in their inclusivity.

We believe that our idea of a transgressive learning community functions as a space of radical pedagogy for the collaborative reflection, discussion, action, and transformation of structures of heteropatriarchal whiteness in academia. As one of our members shared,

[a]fter the culmination of our [transgressive learning community] I started to transform my approach to teaching. On a personal level, I feel more confident to implement novel activities and teaching strategies in my classroom, without fearing failure. I also reflect more on my teaching, documenting my success, the aspects I need to work on, and the ways in which I can improve the teaching and learning experience(s) for my students and I.

As a space that is designed specifically for developing instructors (like us), the transgressive learning community functions not only as a way to address our needs as potential future faculty, but also encourages empowerment and change within — and of — the ivory tower. We acknowledge that similar communities have been created — both formally and informally — at other institutions, as a means to support marginalized students. Here we offer a systematic study of an institutionally formed community 
and discuss the resulting effects. While the model we offer is ultimately grounded in our own institutional context, we hope that readers will be able to adapt it to their own local contexts to serve underprivileged, underserved, and historically underrepresented instructors.

\section{LITERATURE REVIEW}

Hetero-patriarchal, able-bodied whiteness often structures institutions of higher education. In academic settings, knowledge is too often deemed as objective and thus unquestionable. Underprivileged instructors can find it more difficult to dispute objective knowledge, as it is largely taught by instructors imagined as Western, white, male, affluent, heterosexual, and able-bodied. As bell hooks (2003, p. 25) observes,

$[t]$ eachers are often among that group most reluctant to acknowledge the extent to which white-supremacist thinking informs every aspect of our culture including the way we learn, the content of what we learn, and the manner in which we are taught.

These norms are so deeply embedded in the ivory tower that in order to succeed in academia most professors, and the faculty development programs that advance their teaching skills, conform to and sustain these oppressive structures. Teachers who do not conform to this image, like the authors of this article, are advised to abate their identities as a way to avoid disrupting the academic hetero-patriarchal whiteness paradigm. Co-author Jordan Lynton, founder of the transgressive learning community, described this disjuncture as such:

As a young, black woman teaching at a predominately white institution in the midwest I often felt that my students questioned my authority in the classroom - as did I. This questioning of authority led to microaggressions and disrespect on the part of some students, and discomfort, insecurity, and anxiety on my own part. Talking to other instructors of color, I realized that these experiences were not localized to me, but there was no institutional support to help deal with it.

One of the most common learning communities supported in academic contexts is the faculty learning community model that largely responds to undergraduate education concerns (Jessup-Anger, 2015). Based on a community of practice principle that "recognizes that learning is a social and constructed activity which is situated in a particular context" (Engin \& Atkinson, 2015, p. 164; see also Lave 1991), faculty learning communities are groups of cross-disciplinary faculty and personnel. Using guidance from a curriculum, they meet regularly to address specific topics on teaching and learning, to create a space for collaborative learning and development, and to build a professorial community (Richlin \& Cox, 2004). The goals of faculty learning communities vary according to campus needs. However, their overarching objectives often include the following: solve a teaching-related issue, learn collectively, implement a novel teaching strategy, or tackle a specific professional project (Engin \& Atkinson, 2015, p.165). The curricula of faculty learning communities fluctuate, although they are usually designed prior to the beginning of the group's meetings as a way to coach and mentor faculty. Faculty are more likely to use learner-centered teaching practices after participating in faculty learning 
communities than they are after attending a one-off workshop (Grubb, 2006). Furthermore, the faculty learning communities that give its members more autonomy are worthwhile for participants (Daly, 2011). Non-tenure-track and early career faculty have assembled in faculty learning communities to discuss innovative teaching techniques and to reflect on their teaching. Participation in these groups produces favorable results such as an increased sense of professorial community, a more in-depth familiarity with the institution at which they are teaching, and the cultivation of an inclusive environment within their departments or programs (Banasik \& Dean, 2016; Remmik, Karm, Haamer, \& Lepp, 2011).

Faculty learning communities that have been reoriented to serve future faculty are commonly rearticulated as graduate student learning communities. These learning communities serve a distinct academic sector: instructors who are also students at the institution in which they are teaching (Richlin \& Essington, 2004). For graduate students, participation in these groups has emerged as a way to prepare them to teach at higher education institutions. This model's cross-disciplinary and collaborative configuration lays the foundation for the graduate students' future academic careers by addressing their roles as faculty, researchers, and members of an academic community (Richlin \& Essington, 2004). Generally, graduate student learning communities maintain the structural hierarchy of a faculty learning community, relying on the facilitator/participant model in which a facilitator coaches graduate students. Commonly, the facilitator decides on the curriculum and guides participants through the readings, assignments, and events to achieve the set goal(s) for learner-centered instruction. Likewise, facilitators of graduate student learning communities are responsible for fostering a learning environment based on a constructivist approach (Kabes, Lamb, \& Engstrom, 2010).

While the traditional model of learning community for faculty or graduate students has proven successful in a variety of academic settings, it is important to recognize that minority students face unique difficulties when navigating the academic sector. Previous studies have shown that students from marginalized backgrounds often suffer from a lack of academic and social mentoring and support (Gardner, 2008; Lee, 1991; Smith, 1991; Taylor \& Olswang, 1997), absence of diverse faculty mentors and student colleagues (Dumas-Hines, 2001; Smith, 1991), and a racially hostile campus climate (Cabrera, Nora, Terenzini, Pascarella, \& Hagedorn 1999). These factors, in turn, lead to lower retention rates and graduation rates for students from historically underrepresented groups (Seidman, 2005; Clewell \& Ficklen 1986). Assistance for marginalized graduate students must be both continuous throughout all stages of their academic careers and tailored to their specific needs within the academy in order for these students be successful as scholars, researchers, and instructors. Peer support groups (such as graduate student learning communities) help underprivileged, underserved, and historically underrepresented graduate instructors co-create and foster an academic community that can diminish their isolation, exclusion, and sense of invalidation.

In order to empower graduate instructors, however, graduate student learning communities must reconceive their foundations and structures. Traditional structures do not challenge oppressive power relationships in academia, and thus have the potential to further perpetuate the marginalization of underrepresented graduate students. Traditional learning communities follow a hierarchy (facilitators/participants); they tend to respond solely to the concerns of undergraduates' learning, rather than acknowledging identity-related challenges of graduate instructors (although see Warhurst, 2006 for an example of investigating identity transformation during the communities of practice 
process). The majority of graduate student learning communities tailor their goals for specific (i.e., quantifiable) outcomes, not for radical pedagogical reflection. In this way, while the model of learning communities for faculty or graduate students provides vital spaces for discussion and engagement around teaching and learning, they reconstitute in many ways the hegemonic practices and structural inequities that are hazardous to the continued growth of underrepresented peoples within the academy.

Our transgressive learning community reconstructs the traditional model to instead support both praxis (the intersection of practice and theory) and reflexive, subject-centered engagement (Freire 2005. We believe that this intervention is critical in providing safe counter-spaces (Solórzano et al., 2000; Solórzano \& Villalpando, 1998) for those from marginalized backgrounds to engage in difficult topics. Members of the transgressive learning community frequently reiterated that the decentralized discussion and community was one of their greatest takeaways. When asked about what aspects of our transgressive learning community had a long-term impact on them, one member wrote, "Feeling that I'm not alone in my experiences, [and] being connected to colleagues in other disciplines." Another member noted,

[o] ur discussions helped me to rethink the ways in which I situate myself in relation to my students, as well as how I understand authority and my role in the classroom. Ultimately, these factors have made me a more comfortable, confident and supportive instructor for my students.

Furthermore, many members articulated the praxis-centered engagement as empowering, and a practice they later brought back to their own departments and classrooms. One member wrote,

I feel more capable and confident to create equitable learning spaces: from establishing discourse on classroom environments and guidelines, to decentering myself as the locus of knowledge production, and implementing new strategies and activities to deconstruct ideas of power and privilege.

\section{INSTITUTIONAL AND MEMBER CONTEXT}

We, the authors, are graduate students and teaching center staff from a range of disciplinary backgrounds: anthropology, archaeology, biology, public health, and American studies. We share interests in equity-based education and in supporting counter-spaces and counter-storytelling for graduate students of marginalized identities (Ong, Smith, \& Ko, 2017; Solórzano \& Yosso, 2002). Each of us has had roles in the design, implementation, co-facilitation, and continuation of our transgressive learning community. We are at a large, public, residential, four-year, research-intensive university where students, faculty, and staff are predominantly white. The university has more than 40,000 undergraduate students and more than 8,500 graduate students seeking degrees. In addition, our institution is in the Midwest of the United States, a region that is largely economically and socially conservative. At our university, many graduate students receive stipends and tuition waivers for assisting with classes (as the instructor of record, a teaching assistant, or a grader). Although the majority of graduate students who become $\mathrm{PhD}$ candidates are no longer taking classes, they are still considered students until they receive their PhD.

110 Drane, L., Lynton, J., Cruz-Rios, Y., Malouchos, E., \& Kearns, K. (2019). Transgressive Learning Communities: Transformative Spaces for Underprivileged, Underserved, and Historically Underrepresented Graduate Students at Their Institutions. Teaching \& Learning Inquiry, 7(2). http://dx.doi.org/10.20343/teachlearninqu.7.2.7 
The transgressive learning community on our campus emerged in spring 2015, coinciding with several social justice movements in the United States, including the Black Lives Matter movement related to police violence against African Americans; the \#NoDAPL movement in response to infringement on American Indian sovereignty ${ }^{1}$; the \#MeToo movement in response to sexual harassment and assault; and a resurgence of nationalism, nativism, and isolationism both within the United States and around the world. Co-author Katherine Kearns, at the time of writing, a full-time instructional consultant and facilitator, recalled that

[t]wo graduate students of color approached me in fall 2014 about a gap in our servicessupport for graduate student instructors of marginalized identities, including gender, race, nationality, sexual orientation, religion, physical ability, and mental health. Graduate students with non-dominant identities have experiences in their classroom instruction that were not addressed in our "best practices" and one-size-fits-all approach to instructional consulting.

Within these local, regional, national, and international contexts, we advertise the transgressive learning community through departmental email lists and word-of-mouth to encourage graduate students of nondominant identities to join us. In the self-nomination form, we ask respondents to write about teaching or learning challenges related to identity that they face as an instructor. The selfnomination form does not include direct demographic questions about their identities; we do not want to reduce their experiences to numbers or to presume how their identities are an affordance or barrier to their teaching experiences. Often, members mention how their identities as graduate students intersect with marginalized identities of gender, racial/ethnic minority, citizenship, disability, sexual orientation, first-generation college attendance, and low socioeconomic status. Furthermore, these intersecting nondominant identities relate to feelings that they do not belong, stereotype threat, and imposter syndrome; double consciousness (Du Bois, 1903); both hyper-visibility and invisibility; being perceived as incompetent, angry, or biased teachers; experiencing challenges to their authority in their classroom; and noting lack of representation of their concerns and their bodies within the support structures of the institution. For example, co-author and facilitator Yarí Cruz-Rios, described experiences of simultaneous hyper-visibility and invisibility in the classroom:

I am a black Puerto Rican woman, born and raised in the Island, and a native Spanish speaker. In the United States, and especially in a predominantly white institution context, I am always read as "other," no matter how much English I speak, how many times I explain that Puerto Ricans are US citizens, or how many MTV shows I can reference to my students.

Co-authors, Leslie Drane and Elizabeth Watts Malouchos, also facilitators, echoed experiences of struggling with authority as women in a male-dominated field. The liminal identity of graduate students created by simultaneously serving as both learner and instructor, neither fully student, nor fully faculty, is particularly salient and can be disempowering for our members in interactions with both their students and faculty mentors. One member of the transgressive learning community described the interplay succinctly, calling graduate instructors "professionals who are still in the midst of developing 
themselves." These experiences resonated with other authors, such as Gullage (2015), Gutiérrez y Muhs et al. (2012), Harris et al. (2017), and Hoodfar (1992), who detail their own, similar experiences in the intersections of identities and marginalization in the college classroom. Colleagues join the transgressive learning community to find validation, culturally meaningful teaching strategies, and community advocacy for their concerns.

\section{THE TRANSGRESSIVE LEARNING COMMUNITY APPROACH}

Frustrated by our institution's focus on recruitment and yet lack of continuing support for underprivileged, underserved, and historically underrepresented future faculty, a group of graduate student instructors constructed the transgressive learning community as a way of creating spaces of support and discussion for marginalized graduate instructors. Utilizing assistance from the academic institution's teaching and learning center and the graduate school's Emissaries for Graduate Student Diversity Program, they sought to interrupt the perpetuation of instructor isolation and insecurity by creating a space in which graduate students were encouraged to reflect, take action, and create community.

Our transgressive learning community is a feminist (i.e., inclusive and inquisitive) endeavor of diversity work and conocimiento. Gloria Anzaldúa conceives conocimiento as awareness that challenges, "official and conventional ways of looking at the world, ways set up by those who benefit from such constructions" (2002, p. 20). It is knowledge that produces a holistic transformation through an awareness of unequal power structures. Similarly, Sara Ahmed understands diversity work as, "first ... the work we do when we are attempting to transform an institution; and second ... the work we do when we do not quite inhabit the norms of an institution" (2017, p. 90). We designed our transgressive learning community to promote knowledge that is intellectually, physically, and individually aware. As a result, our learning communities emphasize the importance of creating relationships among academic communities and across disciplines. These resulting relationships dismantle dominant narratives by centering the bodies and the voices of those at the fringes of academia and by advocating for the support of underprivileged graduate instructors.

Learning communities that aim to be feminist and inclusive in nature may struggle with management and direction. We recognize facilitators as people who create actions that are fundamental to the understanding and development of graduate student learning communities. Therefore, while we do acknowledge the leadership and organizational work undertaken by the organizing facilitators, we also extend the role of facilitator to all members of our transgressive learning community. As a community of facilitators, we all suggested readings, topics, and actions based on our identities and reflections. Rather than having a set syllabus to work from, the curriculum is adaptable to the identity needs and concerns of each group, and it is flexible to respond to the current events that might affect the teaching roles of underprivileged, underserved, and historically underrepresented graduate students. The texts we study represent different modes of knowledge production and dissemination ranging from peer-reviewed journal articles to podcasts and popular media. Topics we have addressed include identity in the university; identity in the classroom; intergroup dialogue; interpreting course evaluations; student perceptions of diverse instructors, and teaching diversity-related topics (see http://hdl.handle.net/2022/21608 for reading lists).

112 Drane, L., Lynton, J., Cruz-Rios, Y., Malouchos, E., \& Kearns, K. (2019). Transgressive Learning Communities: Transformative Spaces for Underprivileged, Underserved, and Historically Underrepresented Graduate Students at Their Institutions. Teaching \& Learning Inquiry, 7(2). http://dx.doi.org/10.20343/teachlearninqu.7.2.7 


\section{DESIGN OF THE TRANSGRESSIVE LEARNING COMMUNITY}

Each iteration of the transgressive learning community builds upon a basic design that includes face-to-face discussions, self-reflection, and praxis-based community engagement. Below we outline some of the methods we have incorporated into previous transgressive learning community. We had institutional review board approval and member permission to study the design and outcomes of the transgressive learning communities and our institutional climate. We introduce and contextualize our design model to provide guidance and suggestions for those needing to create their own transgressive spaces. However, we emphasize the necessity for context-based learning communities. Each gathering of students should consider their situated personal, institutional, and local contexts while forming their learning community. We believe that building a supportive and intimate peer network should be a central goal of a transgressive learning community. This design concept allows for the creation of inclusive academic spaces that thrive in difference at a scale that facilitates peer-to-peer sharing and connections. We invite readers to consider the approaches below as possibilities for their own transgressive learning communities rather than as prescriptive models.

\section{Discussion-centered transformation}

Following bell hooks' (1994) conceptualization of an engaged pedagogy that fosters well-being, all of our learning communities first focus on the establishment of helpful and healthy relationships, as trust is fundamental to open and productive conversations. We begin by building relationships within our learning communities and then move outward, creating bonds with other academics, our students, and community members.

The members meet bi-weekly to reflect on their teaching experiences, discuss readings from a shared reading list, and share different teaching strategies. As many of our campus's departments do not offer critical pedagogy as part of their curricula, the reading lists provide us with opportunities to delve into the literature. While organizers construct template reading lists, they explicitly state, reinforce, and encourage the idea that members have collective agency to steer the course content, discussion, activities, and outcomes. For example, members of the third transgressive learning community offered additional readings focused on issues of age, disability, and gender.

Our meetings serve as brave spaces for members to discuss issues, situations, and problems unique to our communities (Arao \& Clemens, 2013). Members can respond with stories and advice on how they had or would handle these teaching-related issues. Our engagement with critical pedagogy gives us the language to articulate issues that we struggle with and the ways they relate to larger systems of oppression, while also motivating us to strive for teaching that reciprocally benefits both students and instructors. Furthermore, we push each other to question dominant, traditional forms of academia and brainstorm ways to encourage our students to cultivate similar practices.

Due to the diversity of disciplinary backgrounds within the transgressive learning communities, some members were initially resistant to our prioritization of discussion within meetings. However, in our end-of-program reflections, members often remark that it was through completing the readings and participating in discussions that they realized they were not alone. One member noted, "I initially felt that we were spending a lot of time 'just talking,' but I realized over time that this was exactly what it was all about." Another member reflected, 
[the transgressive learning community] has made me think more clearly about my role in academia, the department and in conversation/confrontation with other colleagues. It has given me a lens with which to interpret my experiences and even though that has been difficult at times-I still think it has been worthwhile in the long term.

Once we build a safe space for discussion we invite practitioners of transgressive and transformative engagement-such as the director of the Graduate Mentoring Center and representatives from Intergroup Dialogue Initiative-to engage in community and join us in our meetings, thus recognizing the ways in which our transgressive learning community was embedded within larger communities of transformative engagement.

\section{Self-reflection study}

In addition to in-person discussions, our use of pre-meeting self-study methodologies allows us to focus on in-meeting dialogue, collaboration, community development and knowledge construction (Coia \& Taylor, 2009; Foot et al., 2014). Methods of self-assessment we have utilized within the transgressive learning communities are journaling, virtual discussions, and activity logs. While the first transgressive learning community incorporated all of these methods, the plethora of parts made it unsustainable for many members, who, as graduate students, had several other responsibilities. For this reason, subsequent communities only incorporated one or two methods; we recommend that future organizers do the same.

\section{Journaling}

Each week, members are prompted to write in a personal journal about their recent teaching experiences. Members are encouraged to think of teaching broadly and do not have to write only about traditional classroom settings. Members utilize a diverse range of recording styles; some people tape themselves talking, others doodle, while a few follow a traditional writing format. Topics range from course highs/lows, responses to discussion questions (see Virtual discussions, below), conflicts they perceived in the classrooms, positive engagements with students, and/or concepts from our readings that they saw reflected in their classrooms. Over time, the journals function as a productive method of self-reflection-a space for members to track patterns within their classroom, to troubleshoot issues and conflict they experience, and to reflect on their growth as a part of the learning community.

\section{Virtual discussions}

Members contribute to online group discussions a few days before our bi-weekly meetings. The discussion site serves as a mediating space between the members' private reflection and assessment (i.e., the journals) and their engagement with other members of the group. Members are given the choice of (1) responding to topics or questions, (2) posting general thoughts about the readings, or (3) posting about specific incidents in their classroom. These virtual discussions become powerful spaces for group members to reflect and connect communally outside of bi-weekly face-to-face meetings. 


\section{Activity logs}

Before each meeting, members complete an activity log asking about teaching challenges and successes for the week. The activity logs are conducted in a survey hosted on Google forms in which members respond to both qualitative questions and quantitative questions about how they are spending their time, types of campus resources they are utilizing, and potential issues impeding their progress, and the like. In the past, this tool provided interesting quantitative data about the group that was useful for organizers, but it did not further the goals of reflection and discussion and thus was phased out of later designs.

\section{Praxis as transgressive practice}

Although our transgressive learning community space allows us to speak freely and openly with one another, we also acknowledge that people outside our learning community have unique perspectives that can shape our conversations and understandings, as well as the institutional power to make sustainable changes toward our goals. In addition, building upon Freire's $(2005,79)$ notion of liberation as praxis, "the action and reflection of men and women upon their world in order to transform it," we recognize that the meanings that we develop within the transgressive learning community have the power to transform the more traditional academic spaces that we, as marginal bodies, engage in on a daily basis.

In order to actualize this transformational potential, we intentionally create spaces where our members can use the knowledge we have gained to share suggestions for how we may improve the academic system for underprivileged, underserved, and historically underrepresented future faculty. These spaces empower group members to engage with topics around diversity and inclusion, as well as center and legitimize their experiences. We encourage members to share their reflections with individuals from a wide variety of other academic settings. These engagements range from events for graduate student instructors and small-scale workshops and discussions with other learning communities - whether for faculty or graduate students - to sessions within both the annual teaching assistant supervisor meeting and teaching assistant orientation. Furthermore, we intentionally share with stakeholders outside of our institution, including learning networks of universities in the United States and Canada, faculty development programs, and both national and regional teaching conferences. These discussions often restructure traditional academic settings to center graduate students from marginalized backgrounds as "teachers" and tenured faculty as "learners." In these ways, the learning community simultaneously exists as a transgressive space while also empowering members to form new transgressive spaces within their own academic communities.

Our transgressive learning community culminates in action on individual and collective levels, reinforcing the idea that learning communities focused on radical pedagogy and identity can/should be flexible rather than fixed. Our reflections demonstrate that an important outcome is the personal transformations of members. By altering the ways in which we think about learning communities, from producing a tangible product to facilitating personal transformations, we can create a model that better serves underprivileged, underserved, and historically underrepresented future faculty. Ultimately, we recognize that our learning communities are successful because we learn from and with one another. This realization causes us to recreate environments of reciprocal learning in our classrooms. As we 
reestablish our agency and power during our learning communities, we transfer these lessons and practices to our classrooms and engagement with faculty.

\section{INSTITUTIONAL PROGRAM ASSESSMENTS}

To inform the long-term development process of a community for marginalized graduate student instructors, organizers of the transgressive learning community solicit responses to application questions, mid-program feedback, and end-of-program assessments. All three forms of assessment also provide evidence for continued institutional commitment and are helpful in securing additional external funding. In their applications, graduate students tell us about their specific instructional challenges with isolation and authority as marked bodies and their ideas for effective support; organizers make specific adjustments to each year's topics and readings based on these application responses. Formative feedback at the semester mid-point informs intentional adjustments to the activities around members' goals. Summative assessments at the end of the semester provide proof of concept and fulfill institutional expectations around member satisfaction and perceived changes in teaching practice (see http://hdl.handle.net/2022/21608 for assessment questions). Throughout the different iterations of the learning communities, we utilize assessment techniques that fulfill institutional values while including assessments that are member-defined and member-focused. The latter is an integral part of our learning community, because traditional institutional assessments do not always address the needs and foci that would produce helpful feedback for learning communities to grow and develop in progressive and helpful manners.

\section{OUTCOMES: EXPANDING COMMUNITY THROUGH PRAXIS}

Beyond the outcomes for members of the group, the transgressive learning community has had a transgressive impact on the teaching center and how its staff members engage with faculty and graduate student instructors about power and oppression in the classroom. For example, readings from the transgressive learning community on feminist and critical race pedagogies that were at first shared among individual staff members are now discussed collectively and institutionally through a monthly reading group on culturally responsive and equity-oriented pedagogy. This knowledge sharing has raised awareness among the teaching center staff about oppressive modes of education and has heightened empathy for the unique challenges of faculty and graduate students of marginalized identities.

In our post-2016 US presidential election climate, our instructors-especially those of marginalized identities - increasingly seek community and additional skills for structuring scholarly discussions around contentious and polarizing topics such as racism, sexism, health care access, free speech, and immigration. The reflection and praxis by members of the transgressive learning communities has influenced the responsiveness of teaching center staff to instructors who teach these particularly difficult topics. The teaching center staff now engage in praxis as they have expanded the breadth of the center's public offerings on classroom diversity, inclusion, and equity topics. Members of the transgressive learning communities are regular partners in the co-design and co-facilitation of these public events. Furthermore, diversity, inclusion, and equity concepts are embedded in all aspects of instructional support (course and lesson design; assignment design and feedback; instructional technology; service learning and civic engagement). A faculty version of the transgressive learning community is sprouting, drawing upon the breadth and depth of resources curated by the members of

116 Drane, L., Lynton, J., Cruz-Rios, Y., Malouchos, E., \& Kearns, K. (2019). Transgressive Learning Communities: Transformative Spaces for Underprivileged, Underserved, and Historically Underrepresented Graduate Students at Their Institutions. Teaching \& Learning Inquiry, 7(2). http://dx.doi.org/10.20343/teachlearninqu.7.2.7 
the transgressive learning communities. Also, teaching center hiring practices are more overtly attuned to addressing implicit biases and to hiring people with diverse experiences.

The presence of the transgressive learning community has brought noticeable interdependence between the teaching and learning center and other offices on campus. The transgressive learning community is now an institutional commitment supported by a graduate student intern funded by a collaboration between the teaching center and the institution's diversity office. Public teaching center events have purposeful university engagement. Collaboratively facilitated by faculty, graduate students, and staff from multiple university communities — such as academics, the health and wellness center, the graduate mentoring center, cultural center directors, and diversity officers in the schools and collegesthey result in reciprocal benefits for the various diversity efforts on campus. This mutual reliance is fostering conversations throughout campus and has deepened institutional understanding of our campus climate. Collaborations created among graduate students, staff in the teaching center, and individuals in the university at large have created a fellowship of individuals eager to bridge gaps concerning diversity, with the hope of enhancing the classroom experience for all. Thus, the effort of inclusion on our campus is becoming work for all of us, not just for the diversity office.

\section{CONCLUSION}

Creating a transgressive learning community by and for underprivileged, underserved, and historically underrepresented graduate instructors and future faculty challenges the assumption that all college and university faculty conform to the white, male, heteronormative status quo. Communities of praxis, like our transgressive learning community, create spaces where marginalized graduate students are legible, validated, and belong. To form our transgressive learning community, we had to consider our situated institutional and local contexts and the limitations in power and agency we held as graduate students and underprivileged, underserved, and historically underrepresented peoples. Because of these structural barriers, we designed our practices to be transformative, but also practical.

The model of the transgressive learning community can be adapted to fit the needs of diverse communities and institutional contexts. For example, future iterations could be easily adapted to suit the needs of junior faculty. Tenured faculty have different conceptualizations of and access to power that junior faculty may not share. A transgressive learning community dedicated to junior faculty or faculty of color may help to disrupt some of those inequities. Another transgressive learning community could be created by and for undergraduate students, or faculty in a specific field. We invite others to construct a transgressive learning community that challenges and transforms their specific institutional environment, and we offer our own experiences and resources as a bridge to transformation.

\section{ACKNOWLEDGMENTS}

We are grateful for the facilitators and members of the four cohorts of the transgressive learning communities, especially Rachel Boveja, who have generously shared their time, empathy, experiences, ideas, and resources. We also thank Greg Siering, Center for Innovative Teaching and Learning;, Maria Hamilton Abegunde, Graduate Mentoring Center; Ciemone Rose co-organizer of the workshop "White Classrooms, Brown Teachers" that helped inspire the first transgressive learning community; and James Wimbush and Yolanda Trevino, University Graduate School, for their personal, professional, and institutional support of the transgressive learning communities. We would also like to thank Emily C. 
Van Alst for providing feedback on this paper and a suggestion for how to make our language more inclusive. The transgressive learning communities and their associated graduate student intern position were supported by an Educational Development Internship Program grant from the Diversity Committee of the Professional and Organizational Development Network; this external grant was matched by the University Graduate School at Indiana University Bloomington.

Leslie E. Drane is a PhD candidate in archaeology in the Department of Anthropology and an Instructional Consultant for the Center for Innovative Teaching and Learning at Indiana University Bloomington (USA).

Jordan Y. Lynton is a PhD student in socio-cultural anthropology in the Department of Anthropology at Indiana University Bloomington (USA).

Yarí E. Cruz-Rios, who received a PhD in American Studies from Indiana University Bloomington (USA), was a PhD candidate while writing this article.

Elizabeth Watts Malouchos is the Research Scientist at the Glenn A. Black Laboratory of Archaeology and a PhD candidate in the Department of Anthropology at Indiana University Bloomington (USA).

Katherine D. Kearns is the Assistant Vice Provost for Student Development for the Graduate School at Indiana University Bloomington (USA). While writing this article, she was a Lead Instructional Consultant at the university's Center for Innovative Teaching and Learning.

\section{NOTES}

1. Our original TLC was founded by women from marginalized backgrounds as a way of creating the spaces that they desired to be a part of in the academy. Spaces in which they were seen, heard, and protected. We called this process a transgression both to incorporate the seminal work of bell hooks as well as to highlight the sometimes difficulty of creating spaces in which "tough" conversations about race, gender identity, sexuality, religion, ableism, and other marginalized identities were commonplace. In 2018, we wrote this article as an argument to encourage other institutions to adopt these transgressive spaces. In our own personal growth, listening, and learning, we have been taught that some of the language we have used in this article is deeply harmful. In particular, our use of "American Indigenous sovereignty" in previous versions of this article, rather than "American Indian sovereignty" negated the political and legal weight of American Indian sovereignty as "American Indian" is the term used in treaties and laws related to Native issues in the United States. This is especially important in this section which describes the infringement on sovereignty at Standing Rock. While recognizing the international reach of this article we wanted to make sure to recognize the sociopolitical distinctiveness of the U.S. context while also upholding solidarity with all Native and Indigenous peoples. In writing this amendment, we also wanted to model the work that we hope our paper does. Our dedication to creating transgressive communities inside and outside of the academy does not mean we are immune to mistakes. However, it does mean that we try (more often than not) to embrace the learning potential that these experiences have and to be transparent when we have done wrong. We are immensely grateful to Emily C. Van Alst who highlighted this issue for us and gave us the opportunity to grow and learn. We encourage you, as a reader, to reach out to us if any of the language or ideas we include in this article cause you and/or your communities harm. Thank you. (This edit was made in August 2020.)

\section{REFERENCES}

Ahmed, S. (2017). Living a feminist life. Durham, NC: Duke University Press. 
Anzaldúa, G. E. (1987). Borderlands/La Frontera: The new Mestiza. San Francisco, CA: Aunt Lute.

Anzaldúa, G. E. (2002). Now let us shift ... the path of conocimiento ... inner work, public acts. In G. E. Anzaldúa and A. Keating (Eds.), This bridge we call home: Radical visions for transformation (pp. 540-578. New York, NY: Routledge.

Arao, B., \& Clemens, K. (2013). From safe spaces to brave spaces: A new way to frame dialogue around diversity and social justice. In L. M. Landreman (Ed.), The art of effective facilitation: Reflections from social justice educators (pp. 135-150). Sterling, VA: Stylus.

Banasik, M. D., \& Dean, J. L. (2016). Non-tenure track faculty and learning communities: Bridging the divide to enhance teaching quality. Innovative Higher Education, 41(4), 333-342. https://doi.org/10.1007/s10755015-9351-6

Cabrera, A. F., Nora, A., Terenzini, P. T., Pascarella, E., \& Hagedorn, L. S. (1999). Campus racial climate and the adjustments of students to college: A comparison between white students and African-American students. Journal of Higher Education, 70(2), 134-160. https://doi.org/10.1080/00221546.1999.11780759

Clewell, B. C., \& Ficklen, M. S. (1986). Improving minority retention in higher education: A search for effective institutional practices. ETS Research Report Series, 1986(1), i-157. https://doi.org/10.1002/j.23308516.1986.tb00172.x

Coia, L., \& Taylor, M. (2009). Co/autoethnography: Exploring our teaching selves collaboratively. In D. L. Tidwell, M. Heston, \& L. Fitzgerald (Eds.), Research methods for the self-study of practice. Self-study of teaching and teacher education practices, 9 (pp. 3-16). Dordrecht: Springer.

Daly, C. J. (2011). Faculty learning communities: Addressing the professional development needs of faculty and the learning needs of students. Currents in Teaching and Learning, 4(1), 3-16. Retrieved from https://www.worcester.edu/Currents-Archives/

Du Bois, W. E. B. (1903). The souls of black folk: Essays and sketches. Chicago: A.C. McClurg \& Co.

Dumas-Hines, F. A. (2001). Promoting diversity: Recommendations for recruitment and retention of minorities in higher education. College Student Journal, 35(3), 190-96.

Engin, M., \& Atkinson, F. (2015). Faculty learning communities: A model for supporting curriculum changes in higher education. International Journal of Teaching and Learning in Higher Education, 27(2), 164-174. Retrieved from http://www.isetl.org/ijtlhe/pdf/ITTLHE1948.pdf

Foot, R., Crowe, A. R., Tollafield, K. A., \& Allan, C. E. (2014). Exploring doctoral student identity developing using a self-study approach. Teaching and Learning Inquiry, 2(1), 103-118. https://doi.org/10.20343/teachlearninqu.2.1.103

Freire, P. (2005). Pedagogy of the oppressed (30th anniversary edition, M. B. Ramos, Trans.). New York: Continuum.

Gardner, S. K. (2008). Fitting the mold of graduate school: A qualitative study of socialization in doctoral education. Innovative Higher Education, 33(2), 125-138. https://doi.org/10.1007/s10755-008-9068-x

Grubb, A. (2006). The impact of a faculty learning community on teaching, learning, \& assessment: The scholarship of teaching and learning in faculty professional development. Internal report, Georgia College \& State University: unpublished. Retrieved from http://www.usg.edu/assets/faculty_affairs/documents/awards06_gcsu-program.pdf

Gullage, A. (2015). Fat lessons: Fatness, bodies and the politics of feminist classroom practice. In T. Penny Light, J. Nicholas, and R. Bondy (Eds.), Feminist pedagogy in higher education (pp. 113-126). Waterloo, ON: Wilfrid Laurier University Press.

Gutiérrez y Muhs, G., Niemann, Y. F., González, G. G., \& Harris, A. P. (Eds.) (2012). Presumed incompetent: The intersections of race and class for women in academia. Boulder, CO: Utah State University Press.

Harris, M., Sellers, S. L., Clerge, O., \& Gooding, F. (Eds.) (2017). Stories from the front of the room: How higher education faculty of color overcome challenges and thrive in the academy. Lanham, MD: Roman and Littlefield.

Hoodfar, H. (1992). Feminist anthropology and critical pedagogy: The anthropology of classrooms' excluded voices. Canadian Journal of Education / Revue canadienne de l'éducation, 17(3), 303-320. Retrieved from http://journals.sfu.ca/cje/index.php/cje-rce/article/view/2636/1945

hooks, b. (1994). Teaching to transgress: Education as the practice of freedom. New York, NY: Routledge.

hooks, b. (2003). Teaching community: A pedagogy of hope. New York, NY: Routledge. 
Jessup-Anger, J. E. (2015). Theoretical foundations of learning communities. New Directions for Student Services, 2015(149), 17-27. https://doi.org/10.1002/ss.20114

Kabes, S., Lamb, D., \& Engstrom, J. (2010). Graduate learning communities: Transforming educators. Journal of College Teaching and Learning, 7(5), 47-55. https://doi.org/10.19030/tlc.v7i5.121

Lave, J. (1991). Situating learning in communities of practice. In L. B. Resnick, J. M. Levine, \& S. D. Teasley (Eds.), Perspectives on Socially Shared Cognition (pp. 63-82). Washington, DC: American Psychological Association.

Lee, C. (1991). Achieving diversity. Issues in the recruitment and retention of underrepresented racial/ethnic students in higher education: A review of the literature. Alexandria, VA: National Association of College Admission Counselors.

Ong, M., Smith, J. M., \& Ko, L.T. (2017). Counterspaces for women of color in STEM higher education: Marginal and central spaces for persistence and success. Journal of Research in Science Teaching, 55(2), 206-245. https://doi.org/10.1002/tea.21417

Remmik, M., Karm, M., Haamer, A., \& Lepp, L. (2011). Early-career academics' learning in academic communities. International Journal for Academic Development, 16(3), 187-199. https://doi.org/10.1080/1360144X.2011.596702

Richlin, L., \& Cox, M. D. (2004). Developing scholarly teaching and the scholarship of teaching and learning through faculty learning communities. New directions for teaching and learning, 2004(97), 127-135. https://doi.org/10.1002/tl.139

Richlin, L., \& Essington, A. (2004). Overview of faculty learning communities. New directions for teaching and learning, 2004(97), 25-39. https://doi.org/10.1002/tl.130

Seidman, A. (2005). Minority student retention: Resources for practitioners. New directions for Institutional Research, 2005(125), 7-24. https://doi.org/10.1002/ir.136

Smith, D. G. (1991). The challenge of diversity: Alienation in the academy and its implications for faculty. Journal on Excellence in College Teaching, 2, 129-137. Retrieved from https://files.eric.ed.gov/fulltext/ED344523.pdf

Solórzano, D., Ceja, M., \& Yosso, T. J. (2000). Critical race theory, racial microaggressions, and campus racial climate: The experiences of African American college students. Journal of Negro Education, 69(1/2), 6073.

Solórzano, D. G., \& Villalpando, O. (1998). Critical race theory, marginality, and the experience of minority students in higher education. In C. A. Torres \& T. R. Mitchell (Eds.), Sociology of education: Emerging perspectives (pp. 211-224). Albany: NY: State University of New York Press.

Solórzano, D. G. \& Yosso, T. J. (2002). Critical race methodology: Counter-storytelling as an analytical framework for education research. Qualitative Inquiry, 8(1), 23-44. https://doi.org/10.1177/107780040200800103

Taylor, E., \& Olswang, S. G. (1997). Crossing the color line: African Americans and predominantly white universities. College Student Journal, 31(1), 11-18.

Warhurst, R. P. (2006). "We really felt part of something": Participatory learning among peers within a university teaching-development community of practice. International Journal for Academic Development, 11(2), 111-122. https://doi.org/10.1080/13601440600924462

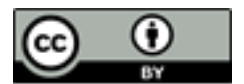

Copyright for the content of articles published in Teaching \& Learning Inquiry resides with the authors, and copyright for the publication layout resides with the journal. These copyright holders have agreed that this article should be available on open access under a Creative Commons Attribution License 4.0 International (https://creativecommons.org/licenses/by/4.0). The only constraint on reproduction and distribution, and the only role for copyright in this domain, should be to give authors control over the integrity of their work and the right to be properly acknowledged and cited, and to cite Teaching \& Learning Inquiry as the original place of publication. Readers are free to share these materials - as long as appropriate credit is given, a link to the license is provided, and any changes are indicated. 